\title{
Expiratory Flow limitation in adult cardiac surgery
}

\section{Saglietti F. ${ }^{1}$, Guarnieri M. ${ }^{1}$, de Simone G. ${ }^{1}$, Di Tomasso N. ${ }^{1}$, Volta C.A. ${ }^{2}$, Bignami E. ${ }^{1}$}

${ }^{1}$ San Raffaele Scientific institute, University Vita Salute San Raffaele, Anesthesia and Intensive Care Unit, Milan, Italy ${ }^{2} S$. Anna Hospital, University of Ferrara, Department of Surgical, Anaesthesiological and Radiological Science, Section of Anaesthesia and Intensive Care, Ferrara, Italy

Background and Goal of Study: Expiratory Flow Limitation (EFL), a functional condition in which expiratory flow cannot increase, is associated with increased incidence of Postoperatory Pulmonary Complications (PPCs) during general anaesthesia ${ }^{1}$.

EFL can be detected by a PEEP test.

This test consists of a sudden subtraction of $3 \mathrm{~cm} \mathrm{H}_{2} \mathrm{O}$ of PEEP; if expiratory flow doesn't increase the patient is considered flow-limited.

The aim of this study is to investigate the incidence and risk factors of EFL during adult cardiac surgery.

Materials and Methods: After the Ethics Committee's approval, we conducted a prospective observational trial. Two hundred patients were continously enrolled from december 2015 to january 2017.

We collected data by the anaesthesia machine: tidal volume, PEEP, $\mathrm{FiO}_{2}$, peak and plateau pressure, lung compliance and EFL.

We analysed 200 patients; Chi-square test was used for dichotomous variables, z-test/t-test or the Mann-Whitney U.test for continous variables, as appropriate.

Statistical significance if $p<0,05$.

Results and Discussion: Our sample was composed mostly by males(130;65\%), with a mean age of $61,92( \pm 14,18)$ years and a BMI of $26( \pm .5,04)$.

The number of redo was $28(14 \%)$, and the most performed surgery was valvular surgery $(111 ; 55,5 \%)$.

31 patients(15,5\%) presented EFL immediately after anaesthesia induction.

At the end of the surgery 62 patients (31\%) showed EFL; 78 patients (39\%) had least one EFL troughtout the surgery.

Patients who presented EFL at the beginning of the surgery had a significantly higher incidence of $\mathrm{PaO}_{2} / \mathrm{FiO}_{2}$ ratio $<200$ at $\mathrm{ICU}$ discharge $\left(32,3 \%\right.$ vs $\left.14,2 \% ; X^{2}=6,05 ; p=0,02\right)$ and need of NIMV (48,4\% vs $29 \% ; X^{2}=4,52$; $p=0,038$ ).

Being flow-limited during any time of the surgery resulted in lower $\mathrm{PaO}_{2} / \mathrm{FiO}_{2}$ ratio at ICU discharge $(273,4 \pm 121,3$ vs $316,87 \pm 111,9 ; p=0,012)$, higher need of NIMV $\left(42,31 \%\right.$ vs $\left.25,41 \% ; X^{2}=6,24 ; p=0,012\right)$.

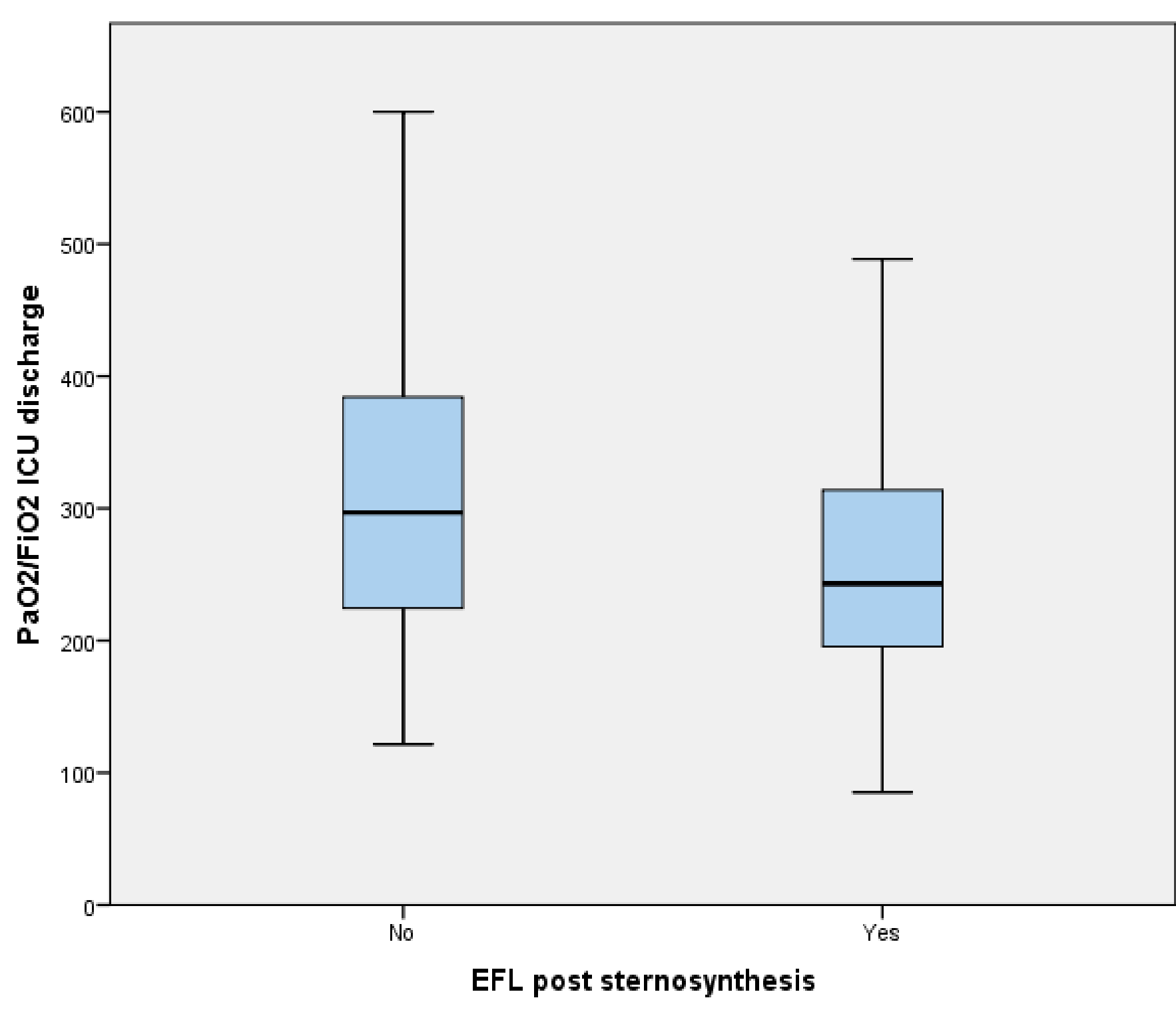

Conclusion(s): Assessing EFL during general anaesthesia is easy and feasible, EFL monitoring could be used to identify patients at risk of PPCs and allow the implementation of protective ventilation strategies. 